\title{
Medical management of Captured Persons
}

\author{
Robin G Simpson, ${ }^{1}$ D Wilson, ${ }^{2}$ J J Tuck ${ }^{3}$
}

\begin{abstract}
In most conflicts there is the potential that there will be Captured Persons (CPERS) whose medical care is the responsibility of the capturing army. The standard of this care should be to the same standard as that afforded to one's own troops. However the medical practicalities of maintaining such standards can be difficult. This article reviews the practicalities of the medical care of CPERS as part of the UK deployment in Afghanistan on Operation HERRICK.
\end{abstract}

\section{INTRODUCTION}

The current campaign in Afghanistan (Op HERRICK) has seen military forces deployed in asymmetric, counterinsurgency and nation building roles almost simultaneously. There have been two key campaigns in Iraq and Afghanistan, and each has resulted in forces of the coalition nations taking individuals into detention.

Following the Public Inquiry into the 2003 death of Baha Mousa (and legal action against the perpetrators) Sir William Gage's recommendations have been the basis for the development of those actions, policies, processes and procedures necessary to govern how individuals conduct themselves when dealing with persons detained during times of conflict. These doctrines are based on the fundamental declarations of human rights and the Law of Armed Conflict (LOAC). ${ }^{1-5}$ This process has seen some old dilemmas re-emerge to challenge professional standards and ethics. ${ }^{6-8}$

It has been suggested that medical professionals have become complicit in abuse at worst, or at least complacent in discharging their duties to patients whose legal status is unclear. ${ }^{9-11}$ A powerful factor is that of dual loyalty, where the individual has to balance the medical needs of their patients, who happen to be CPERS, with their military duty or to national policies concerning detained persons or to tacitly

\footnotetext{
${ }^{1}$ Whittington Barracks, Lichfield, Staffordshire, UK ${ }^{2}$ Royal Centre for Defence Medicine, Birmingham, UK; ${ }^{3}$ Headquarters 3 (UK) Div, Salisbury, UK

Correspondence to Col R G Simpson, L/RAMC, GP Dean, DHET, Whittington Barracks, Lichfield, Staffordshire WS14 9PY, UK;

simpsonrg1@btopenworld.com
}

condoning the actions of their colleagues and friends by failing to act when there is evidence of questionable behaviour. ${ }^{12-16}$

The medical literature concerning individuals detained during conflict is limited and mainly from US experiences. There are papers discussing the legacy health issues of prisoners of war from WW2, ${ }^{17}$ Korea, ${ }^{18}{ }^{19}$ Vietnam $^{20}$ and the US experience in the Gulf in Operation Desert Storm in $1991 .^{21}$ There are a limited number of publications concerning the care and management of prisoners taken during the Gulf War of 1991. These papers have merely outlined how the expressed needs were managed in the hospital $^{22-24}$ and primary care 25 settings and some authors have suggested that health seeking behaviours might be used as a means of subverting the resources of the detaining power. ${ }^{27}$ However, with the current high profile of CPERS within the UK and the publication of the Baha Mousa Inquiry Report, ${ }^{28}$ policy, practice and process is now being looked at from a clinical perspective. ${ }^{29}$ Soon after the case of Baha Mousa came to light, the UK's Defence Medical Services' Surgeon General directed that medical policy concerning detained persons be reviewed. This was effected through a Surgeon General's Policy Letter in $2009^{31}$ (having been first issued in 2005 and revised in 2007). In October 2011, Joint Doctrine Publication (JDP) 1-10 was issued, ${ }^{32}$ outlining how the UK military would approach the subject of the management of CPERS in an integrated way, and taking into account the duties and responsibilities of all those engaged in the medical management of CPERS. In Afghanistan, the revised Joint Doctrine Publication is being implemented in both the primary and secondary care settings.

\section{CPERS ON CURRENT OPERATIONS}

The aim of this paper is to highlight areas where policy and practice have developed to support CPERS, identify areas where the doctrinal principles might be difficult to deliver in a meaningful way and discuss the issues that require review to ensure that CPERS receive the treatment they require in an environment that is secure but appropriate in clinical, cultural and security terms.
JDP1- $10^{32}$ reflects military guidance resulting from recent operations on all aspects of the CPERS activities. It discusses aspects of CPERS, including defining the standards of medical care, which are "equivalent to those applied to members of the UK Armed Forces". Chapter 3 defines the United Nations' Principles of Medical ethics regarding CPERS (Figure 1).

While these principles are clear, the reality of delivering care to CPERS is frequently not straightforward. The duties and responsibilities of a military GP looking after CPERS will be complex and require an experienced practitioner with the necessary experience of dealing with uncertainty, effective consulting skills and an awareness of working in a transcultural environment, including communicating through interpreters. They will also require sufficient authority and independence to be able to act as effective advocates for their patients.

\section{TIMELINES}

Even before a CPERS sees a doctor, there is considerable process that has to be completed to ensure that these individuals can be shown to have been administered and cared for by the "Detaining Authority" to the required standard. The JDP states that "CPERS must undergo a medical examination within 4 bours of capture, unless there are compelling circumstances making such examination impossible. This examination should be conducted by the most medically qualified individual available". These medical assessments are routine for all CPERS; should a CPERS present injuries requiring emergency medical attention, they would be medically evacuated as a matter of priority. On Operation HERRICK 15, this timeline for routine medical examination was frequently difficult to meet for operational reasons, particularly the availability of transport to evacuate the CPERS. In order to meet the spirit of the doctrine it was felt that, in the Afghan theatre, "screening medicals" were to take place at the point of capture. These medicals were to be undertaken by the most qualified medical person present (Combat Medical Technician (CMT), General Duties Medical Officer (GDMO) or Medical Officer (MO)) and specifically addressed two questions: "Did the CPERS require any immediately necessary treatment?" and "Did the CPERS have any obvious injuries?"

The CPERS capture card was annotated to declare whether there was, or was not, any immediate treatment needed or visible 
Figure 1 United Nations' Principles of Medical ethics surrounding captured persons (CPERS).

\section{Principle 1 - Duty to Treat}

Health personnel, particularly physicians, charged with the medical care of CPERS have a duty to provide them with protection of their physical and mental health and treatment of disease of the same quality and standard as is afforded to those who are not imprisoned or detained.

\section{Principle 2 - Prohibition of Mistreatment}

It is gross contravention of medical ethics, as well as an offence under applicable international instruments, for health personnel, particularly physicians, to engage, actively or passively, in acts which constitute participation in, complicity in, incitement to or attempts to commit torture or other cruel, inhuman or degrading treatment or punishment.

\section{Principle 3 - Professional Relationships}

It is a contravention of medical ethics for health personnel, particularly physicians, to be involved in any professional relationship with CPERS the purpose of which is not solely to evaluate, protect or improve their physical and mental health.

\section{Principle 4 - Impartiality of Treatment}

It is a contravention of medical ethics for health personnel particularly physicians: To apply their knowledge and skills in order to assist in the interrogation of CPERS in a manner that may adversely affect the physical or mental health or condition of such CPERS and which is not in accordance with the relevant international instruments;

- To certify, or to participate in the certification of, the fitness of CPERS for any form of treatment or punishment that may adversely affect their physical or mental health and which is not in accordance with the relevant international instruments, or to participate in any way in the infliction of any such treatment or punishment which is not in accordance with the relevant international instruments.

\section{Principle 5 - Restrictions on Restraint}

It is a contravention of medical ethics for health personnel, particularly physicians, to participate in any procedure for restraining a CPERS unless such a procedure is determined in accordance with purely medical criteria as being necessary for the protection of the physical or mental health or the safety of the CPERS himself, of his fellow CPERS, or of his guardians, and presents no hazard to his physical or mental health.

\section{Principle 6 - Prohibition of Derogation}

There may be no derogation from the foregoing principles on any ground what so ever, including public emergency.

used". However the concept of consent is difficult to translate. The CPERS may not understand fully this principle and sign with his thumb print to please those present. Although this was not the intention of the Medical Officer trying to obtain consent, it again demonstrates the complexity of trying to ensure "western" ethical principles are maintained in a different cultural setting. Additionally there is a question about the quality of the consent received from a newly captured CPER who is very likely to feel threatened. This needs to be factored against the clear need to establish and see to the medical needs of the CPER and emphasises the need for a clear interpretation to explain the purpose of the examination.

\section{COMIMUNICATION}

In the CPERS environment, the entire consultation process becomes more complex. Interpreters may be nervous about working in a detention centre and may insist on covering their faces for their own security. Whilst this may be a sensible personal security measure, the CPERS may be less likely to talk freely and it may hamper non-verbal communication as well. A close trusting relationship between the $\mathrm{MO}$ and interpreter can greatly enhance the communication with the CPERS, but the MO may have no say in the choice of interpreter. CPERS are frequently, unsurprisingly, anxious which may affect the way they present their health needs. Assessing CPERS under 
such circumstances requires the clinician to differentiate between appropriate anxiety, mental ill health or a physical illness. This can be easier after the CPERS has spent a few days in a detention centre, where they can be closely monitored, with daily medical review if needed.

Whilst the consultation can be more complex than usual, ethical considerations introduce their own complications, as outlined below. Notwithstanding this, the principles of medical ethics for CPERS are clear and the physician must provide standards of medical care, confidentiality and documentation equivalent to those applied to members of the UK Armed Forces. $^{32}$

\section{PRE-EXISTING ILLNESS}

An example of such an ethical labyrinth might be the diagnosis of moderate hypertension. The first matter to consider is whether the hypertension is a result of the anxiety of capture (sometimes termed "shock of capture") or is it a chronic illness? There is unlikely to be a record of the individual's medical history to inform the situation. Should the clinician initiate medical treatment which would be required on a long-term or enduring basis, despite it being unlikely that it will be continued after release? Drugs in Afghanistan are expensive and long term monitoring and treatment is unlikely to be affordable to the majority. This is further complicated because it is frequently not known how long the patient will remain a CPERS. It would be unrealistic to start a series of procedures or investigations, only for the CPERS to be "moved" or released from UK custody at short notice.

Furthermore, starting therapy such as a Beta Blocker may cause rebound hypertension if the treatment is stopped abruptly which may cause more harm than good. Western protocols for the management of hypertension use age as a factor; however, few Afghan men know their age and no long term cohort studies have been conducted on hypertension in Afghan populations. Similar considerations might apply to the management of any chronic disease requiring long term follow up and treatment.

Health seeking behaviour will also influence the consultation. In Afghanistan, an adult patient will expect a prescription from their doctor and it is not uncommon for adults to have multiple, often unknown, medications in their pocket. On arrival at the detention centre the clinician then has to decide on the appropriateness of the treatment. CPERS may try and use medical issues to gain some benefit while in detention and the clinician has to decide on the appropriateness of their complaint or condition.

\section{MENTAL HEALTH}

Assessing the mental health of a CPERS can be difficult. The health beliefs of the CPERS population vary from those of the Western trained doctor. Afghan males may express their anxiety as "an attack of the fairies"; sometimes expressions of mental health symptoms are attempts to express unhappiness with detention. The clinician then has to decide if this is a separate mental health issue or a consequence of the individual's detention. For example, the detainee may express frustrations with detention as psychosomatic complaints such as headaches. Detainees often complain of "whole body pain" which has been present for many years. Good clinical method can help in these cases but it must be remembered that western models of mental health may not translate into other cultural settings. For chronic pain of no apparent origin, the clinician may have to try medication without a clear understanding the nature of the complaint.

\section{MANAGEMENT OF CPERS AT ROLE 3}

CPERS not infrequently sustain injuries immediately prior to or during the process of capture, particularly if they engage in kinetic activity during the operation in which they are later detained. On occasion, CPERS' injuries are of sufficient severity to warrant admission to hospital. As CPERS are afforded the same standard of medical care as coalition soldiers they are prioritised according to need, evacuated through the medical evacuation system and admitted to Role 3 Medical Treatment Facilities. Whilst there are no conceptual or physical issues concerning the prioritisation and management of CPERS there are certain social issues that might cause tension or confusion. Treating CPERS alongside those they have been in direct conflict with clearly presents potential difficulty and the appropriate use of screens and darkened goggles to protect the identity of both CPERS and hospital staff, especially locally employed civilians and interpreters, is a necessary intervention.

Language and cultural barriers can be problematic in the hospital setting, for example when consent for surgical intervention is required. Detailed explanation of complex procedures, including possible requirement for amputation, may be beyond the translation skills of the embedded interpreters, while understanding and completion of the consent form is challenging for individuals with no literacy skills - even where forms are produced in appropriate local languages. Training of clinical staff in ethics and utilisation of the two doctor consent process, help mitigate against this issue.

A further challenge lies in CPERS accessing follow on care involving more highly specialised services. CPERS care can be enhanced by outpatient visits to Role 3 departments such as physiotherapy, although these visits must be seen in the context of acute management and not one of rehabilitation. Caution should be exercised before embarking on any long term care pathway for CPERS. In particular, as CPERS cannot be transported to the UK for Role 4 care, this means that questions will arise as to the most appropriate longterm treatment or rehabilitation for CPERS and creates the potential for prolonged Role 3 admissions and consequent threat to capacity. This should be factored into the CPERS' medical assessment. CPERS are eligible for transfer to units providing specialist care, such as for neurosurgery in Kandahar on Op HERRICK. Difficult decisions arise when long bone fractures are suitable for internal fixation ${ }^{33}$ - a treatment not offered to UK personnel who can return to Role 4 for definitive care. A balance needs to be struck between providing treatment that will maximise, and shorten, recovery and the potential for long-term complications that cannot easily be managed in Afghanistan health-care system.

\section{SECURITY}

The fact that CPERS are possible enemy combatants represents a potential threat to the security of the hospital which must be acknowledged and mitigated. This presents many complex issues and clashes of professional duty where guarding, segregation and possible restraint of a patient can be at odds with the notion of caring. However, all CPERS are screened and guarded whilst in hospital, ensuring that they are unable to gather information from the immediate environment, maintaining the anonymity of other patients, uniformed military staff and, most importantly, locally employed civilians. In addition to the screening-off of CPERS, darkened goggles are provided when moving through the hospital.

Guards are provided from a variety of sources and are not medical personnel. Initially the responsibility for providing guards falls to the capturing unit, reverting later to Force Protection or the Military Provost Team. CPERS detained 
by other nations, such as the USA, remain their responsibility and must be guarded by that nation. All guards must be briefed thoroughly on their role (including medical confidentiality, appropriate use of restraint and not obstructing medical care).

\section{RESTRAINT}

Present policy on Operation HERRICK states that CPERS should not be restrained unless there is an assessment that the individual continues to present a physical threat. In this instance, the Commanding Officer, in consultation with the Deployed Medical Director, will sanction the use of physical restraint, to be used with the minimum force necessary and for the shortest possible time.

\section{DISCHARGE FROM HOSPITAL}

Discharge of CPERS from hospital often presents the most difficult challenges. Those that recover well from their injuries and reach a stage of treatment where they are fit for discharge will be subject to further review by an appropriate MO from the holding facility to which they will be discharged to ensure that the individual is capable of undertaking the routine of daily life in the facility. This decision will be based on a review of the on-going clinical needs and a functional assessment undertaken by a physiotherapist, during which the ability of the CPERS to walk and undertake basic functions including squatting (for toileting) is assessed.

This discrepancy between fitness for hospital discharge and fitness for holding in the detention facility can result in prolonged hospital stays for on-going rehabilitation. This can threaten hospital capacity and can lead to friction between primary and secondary care teams. Communication, both verbally and in written summaries, is vital both for the passage of information and for the establishment of a robust audit trail.

\section{LIAISON WITH DETAINING AUTHORITIES}

Close liaison with the authorities responsible for arresting and detaining CPERS is crucial. Clarification of the status of an incoming casualty as a CPERS at the earliest possible stage allows for appropriate security measures to be instituted immediately rather than added later.

If a CPERS is not going to reach the fitness and capability threshold for detention then discussion is required to determine whether the CPERS can be de-classified and treated as a local national civilian. This presents particular difficulties during or after prolonged stays on the Intensive Care Unit when even de-classification leaves problems of transfer to the host nation facilities which often have no critical care provision.

\section{SUMIMARY}

The purpose of Joint Doctrine Publication 1-10 'Captured Persons (CPERS)' [Second Edition] is to provide high level joint doctrinal guidance on how to deal with persons who fall into the hands of UK Armed Forces during military operations, whether Prisoners of War (PW), civilian internees or those detained as a result of suspected or actual criminal activity. JDP $1-10$ is written for the benefit of all UK Armed Forces personnel, and further provides doctrinal guidance to commanders in regards to compliance with domestic UK law, international law and the LOAC.

Despite the clarity of the document, there are a number of areas where the following of this policy raises ethical and practical difficulties. Timelines for moving CPERS from point of capture back to a formal detention centre will be tight and realistically may fall outside 4 hours. The care of CPERS during this period may be by CMTs or GDMOs. A number of issues such as consent may seem straightforward until applied to a CPERS who has no cognisance of western medicine. If the CPERS has a pre-existing illness, how appropriate would the pathway for UK military patients be in treating and managing their condition? Medications readily available in UK (and the drugs of choice) may not be available to the CPERS on release from captivity. If a CPERS who presents additional challenges to personnel (for example, a physical threat) requires admission to the Role 3 Facility, on-going balancing may be required between providing the best possible medical care and ensuring the safety of hospital personnel (for example, by appropriate restraint of the CPERS). Guards will also be required to accompany CPERS on hospital wards and this will inevitably upset the ambiance of a Role 3 Facility. Discharge of CPERS from the Role 3 is likely to mean admission to a detention facility.

The inability of CPERs with on-going disability to function within such a facility, which does not have medical bedding down capability, may result in prolonged stays in a Role 3 facility with potential impact on its capacity and capability.
The new JDP is a welcome document giving excellent guidance to all members of the Armed Forces on CPERS and this paper raises a number of issues for consideration when applying the standards laid down in that strategic policy document.

Contributors RGS is the lead author and is responsible for the article. He was assisted equally by DW and JJT. All three authors significantly contributed. The article was planned by all 3 authors.

Disclaimer The views expressed are those of the authors and not necessarily those of the MOD. The paper has had Security Clearance from the Surgeon General Department and the MoD.

\section{Competing interests None.}

Provenance and peer review Not commissioned; externally peer reviewed.

To cite Simpson RG, Wilson D, Tuck JJ. J R Army Med Corps 2014;160:4-8.

Received 16 March 2013

Accepted 21 March 2013

J R Army Med Corps 2014;160:4-8.

doi:10.1136/jramc-2013-000064

\section{REFERENCES}

1 Geneva Conventions of 1949 and their additional protocols. www.icrc.org/war-and-law/treatiescustomary-law/geneva-conventions/index.jsp (accessed 14 Jan 12).

2 UN GA RES 543(VI). UN International Bill of Human Rights. 1952.

3 A/RES 39/46 UN Convention Against Torture and Other Cruel, Inhuman and Degrading Treatment and Punishment. 1984

4 A/RES 45/111. The Basic Principles for the Treatment of Prisoners. 1990.

5 A/RES 37/194. The Principles of Medical Ethics relevant to the role of health personnel, particularly Physicians, in the Protection of Prisoners and Detainees against Torture and Other Cruel, Inhuman or Degrading Treatment or Punishment. 1982.

6 Strauss SA. Legal aspects of medical treatment of prisoners and detainees. Med Law 1989;7:551-5.

7 Singh JA. Treating war detainees and terror suspects: legal and ethical responsibilities of military physicians. Mil Med 2007;172(12 suppl):15-21.

8 Place RJ. Caring for non-combatants, refugees, and detainees. Surg Clin North Am 2006;86:765-77.

9 Miles SH. Medical ethics and the interrogation of Guantanamo 063. Am J Bioethic 2007;7:5-11.

10 Miles SH. The new military medical ethics: legacies of the Gulf War's the War on Terror. Bioethics 2013;27:117-23.

11 Howe EG. Dilemmas in military medical ethics since 9/11. Kennedy Inst Ethics J 2003;13:175-88.

12 Clark PA. Medical ethics at Guantanamo Bay and Abu Ghraib: the problem of dual loyalty. J Law Med Ethics 2006:34:570-80, 481.

13 Rosner $F$. Ethical dilemmas for physicians in time of war. Isr Med Assoc J 2010;12:133-5

14 Benatar SR, Upshur RE. Dual loyalty of physicians in the military and in civilian life. Am J Public Health 2008:98:2161-7.

15 Singh JA. American physicians and dual loyalty obligations in the "war on terror". BMC Med Ethics 2003;4:E4.

16 Gesundheait B, Ash N, Blazer S, et al. Medical care for terrorists - to treat or not to treat? Am J Bioeth 2009:9:40-2.

17 Robson D, Welch E, Beeching NJ, et al. Consequences of captivity: health effects of far East 
imprisonment in World War II. QJM 2009:102: 87-96.

18 Hunt SC, Orbson M, Checkoway H, et al. Later life disability status following incarceration as a prisone of war. Mil Med 2008:173:613-18.

19 Ritchie EC. Psychiatry in the Korean War: perils, PIES, and prisoners of war. Mil Med 2002;167:898-903.

20 Kaiser $A P$, Clark CL, King LA, et al. Long term effects of coping with extreme stress: a longitudinal study of Vietnam Era repatriated prisoners of war. J Trauma Stress 2011;24:680-90.

21 Steinfeld R, Baggett JC, Mitchell RE. Orthopaedic injuries experienced by US prisoners of war during operation desert storm: a descriptive analysis. Mil Med 1995;160:175-7.

22 Wintermeyer SF, Pina JS, Cremins JE, et al. Medical care of Iraqis at a forwardly deployed U.S. Army hospital during Operation Desert Storm. Mil Med 1996;161:294-7.

23 Kennan WF. Non-surgical medical care of enemy prisoners of war during Operation Desert Storm. Mil Med 1991;156:648-51.

24 Longmire AW, Deshmukh N. The medical care of Iraqi enemy prisoners of war. Mil Med 1991;156:645-8.

25 Tuck JJ. Medical management of Iraqi enemy prisoners of war during Operation Telic. Mil Med 2005; 170:177-82.

26 Murray CK, Roop SA, Hospenthal DR. Medical problems of detainees after the conclusion of major ground combat during Operation Iraqi Freedom. Mil Med 2005;170:501-4.

27 Cappucci DT Jr, Flemming SL. Medical observations of malingering in Iraqi enemy prisoners of war during Operation Desert Storm. Mil Med 1994;159:462-4.
28 Right Honourable Sir William GageReport. http:/l www.bahamousainquiry.org/ (accessed 13 Jan 2013).

29 Moy RJ. Ethical dilemmas in providing medical care to captured persons on operations. J R Army Med Corps 2012;158:6-9.

30 McNeill Love RMC. Commentary. J R Army Med Corps 2012;158:9.

31 DMSD29/5/3, Medical Support to Persons Detained By UK Forces Whilst on Operations Dated 2009.

32 JDP1-10 Captured Persons Version 2. 2011.

33 Beech Z, Parker P. Internal Fixation on Deployment: Never, Ever Clever? The limb trauma working group, academic department of military surgery and trauma royal centre for defence medicine, Birmingham. $J R$ Army Med Corps 2012;158. 